\title{
Effects of Nano-Silica modified Self-Compacted, High Volume Fly Ash Mortar on Slump Flow and Compressive Strength
}

\author{
Veerendrakumar C Khed, Bashar S Mohammed ${ }^{\star}$ and Muhd Fadhil Nuruddin \\ Department of Civil and Environmental Engineering, Universiti Technologi Petronas, Seri Iskandar, Perak, Malaysia
}

\section{Article Info \\ *Corresponding author: Bashar S Mohammed \\ Associate professor \\ Department of Civil and Environmental \\ Engineering \\ Universiti Technologi Petronas \\ Seri Iskandar, Perak, Malaysia \\ E-mail:bashar.mohammed@petronas.com.my}

Received: July 6, 2016

Accepted: July 18, 2016

Published: July 23, 2016

Citation: Khed VC, Mohammad BS, Nuruddin MF. Effects of Nano-Silica modified SelfCompacted, High Volume Fly Ash Mortar on Slump Flow and Compressive Strength. Madridge J Nanotechnol Nanosci. 2016; 1(1): 9-12

doi: $10.18689 / m j n n-1000104$

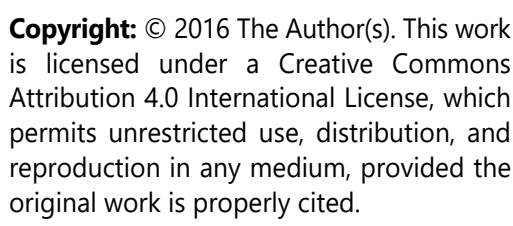

Published by Madridge Publishers

\begin{abstract}
The purpose of this study is to establish the effects of nanosilica on high volume fly ash self-compacted mortar. The nanosilica was added from zero to $5 \%$ in mortar containing $70 \%$ fly ash replacement to cement. The flowability of 240 to $260 \mathrm{~mm}$ has been maintained by varying the polycarboxylic based super plasticizer. It has been observed that nanosilica had adversely effects the workability. On the other hand, nanosilica mitigated loss of compression strength due to high volume of fly ash replacement. The compressive strength of mortar containing $70 \%$ of fly ash replacement to cement and $5 \%$ addition of nano-silica has been improved by $94 \%$.
\end{abstract}

Keywords: Nano-silica; Compression strength; Fly ash mortar; Plasticizer.

\section{Background}

The conventional concrete has few disadvantages mainly with its differential compaction, its durability and noise caused by the vibrating instrument. This has encouraged the researchers to develop self-compacting concrete (SCC). In SCC the mortar ingredients play an important part for better performance. Since the mortar is crucial for fluidity thus compacting on its own and it lubricates the coarse aggregate, thus it brings coarse aggregates nearer to each other. In this study the workability and compression strength of self-compacting cement mortar utilizing the binary products such as high volume fly ash and nanosilica had been carried out.

Utilizing high volume fly ash (HVFA) as cement replacement in SCC tends to be a possible solution, with reduction in cost of cement, improvement of workability. Although fly ash has a negative effect on the early strength development of concrete. Utilizing Nano Silica (NS) in high volume fly ash can be a possible solution to problem related to the strength loss in SCC, and the early poor strength development of HVFA in SCC due to NS high pozzolanic reaction, filler effect, and activation of fly ash pozzolanic reactivity.

Once upon a time, microsilica or silica fume, materialized to be a better pozzolanic cementitious substance, since it is a small in size which has the ability of high packing. In addition, silica fume are non-crystalline in its nature with more specific surface area and thus it reveals a high pozzolanic activity. In various applications, silica fume in partial replacement with cement had improved the hardened properties of cement paste [1-5]. In more recently the nano technology has been introduced in concrete containing nano materials in the form of nonosilica which is available in the market. Nanosilica is high pozzolanic material when compared to silica fume. Nanosilica is ultrafine in size to nanometer $\left(1 \times 10^{-9}\right)$. 
It is produced synthetically which is water emulsion amorphous colloidal silica. Hence it can be replaced with silica fume due to its high percentage content of amorphous silica [6]. Nano silica improves concrete mechanical properties, durability, lower the setting time, reduces the overall cost of construction [7]. Also, Nano silica is a highly reactive filler when used in concrete even at lower percentage and it densified the concrete micro structure, increase rate of hydration, reduces bleeding, reduces initial and final setting time in fly ash concrete and improves early strength development in fly ash concrete $[7,8]$.

H.Li et al. $[9,10]$, studied the inclusion of nano materials like nonosilica and nano-ferric-oxide particles of size $10 \mathrm{~nm}$ in cement mortar, they found the increase of compression strength by $26 \%$ when compared with the control mix of cement mortar. Additionally, the concrete using nanoparticles had improved the abrasion resistance and pavement performance under the repetitive loads (fatigue loads) [11, 12]. Mondal.P et al [13] and Senff.L et al. [14] had worked on the effect of fresh properties like flowability and setting time, they found that flow decreases as the nanosilica addition increased and they also suggested that nanosilica in cement mortar had improved the strength and durability. BW. Jo et [15] explored the nanosilica modified cement mortar using $40 \mathrm{~nm}$ size nano particles, they notified that strength increase about $170 \%$ on control mortar mix and $100 \%$ on silica fume mixture and also they had described that nanoparticles behaved like a nucleus in bonding the hydrated cement, a strong gel structure formed, therefore it improved the hardened mechanical properties. Chen et al [16] also investigated that nanosilica improved the compressive strength when compared with cement mortar comprising silica fume. Tang.M et al. [17] analyzed the SEM (scanning electron microscope) and X-Ray diffraction for comparing on cement mortar containing silica fume and nanosilica.

Lin et al [18] found the effect of nano materials on cement paste microstructure, their outputs were that the addition of nano particles in cement mortar increased the crystallization density, as higher the nano particles the more denser the crystallization and also the pore sizes were small and lesser in number.

JY Shih et al. [19] investigated that the nanosilica might fill the capillary pores and thus it leads to better pozzolanic activity. The cement mortar using nanoparticles were significantly improved the microstructural property and thus progressing towards its compressive strength and low permeability [20].

\section{Experimental programme Materials}

The materials used in this experiment were ordinary Portland cement (OPC) which confirm to ASTM C150, class F fly ash which has overall amount of oxides $88.5 \%$ i.e. silicon $\left(\mathrm{SiO}_{2}\right)$, aluminum $\left(\mathrm{Al}_{2} \mathrm{O}_{3}\right)$ and iron $\left(\mathrm{Fe}_{2} \mathrm{O}_{3}\right)$ and loss of ignition below $6 \%$ according to ASTM C618, and nanosilica containing $99.8 \%$ of $\mathrm{SiO}_{2}$. The chemical arrangements of the cementitious and pozzolanic materials are given in Table 1.Clean mixing water according to ASTM C 1602 with polycarboxylic based superplasticizer "Sika Viscocrete 2044" and river sand as fine aggregate.

Table 1: Chemical configuration of the cementitious and pozzolanic materials.

\begin{tabular}{|c|c|c|c|}
\hline Chemicals composition/proportions & Cement (\%) & Fly ash (\%) & Nanosilica (\%) \\
\hline $\mathrm{SiO}_{2}$ & 25.21 & 64.69 & 99.8 \\
\hline $\mathrm{Al}_{2} \mathrm{O}_{3}$ & 4.59 & 18.89 & - \\
\hline $\mathrm{Fe}_{2} \mathrm{O}_{3}$ & 2.99 & 4.9 & - \\
\hline $\mathrm{CaO}$ & 62.85 & 5.98 & - \\
\hline $\mathrm{MgO}$ & 1.7 & 1.99 & - \\
\hline $\mathrm{Na}_{2} \mathrm{O}$ & 0.98 & 2.41 & - \\
\hline $\mathrm{K}_{2} \mathrm{O}$ & 1.68 & 1.14 & - \\
\hline Specific gravity & 3.15 & 2.3 & - \\
\hline Loss of ignition & 2.02 & 1.87 & 6 \\
\hline
\end{tabular}

\section{Mix proportions}

The concrete mix design for the control mix (without fly ash and nanosilica) of grade $40 \mathrm{MPa}$ had been carried out according to $\mathrm{ACl}$. For self-compacting concrete EFNARC guidelines were incorporated. The paste ingredients from the concrete mix design had been utilized for the experiment. In the first part the cement was replaced by fly ash up to $90 \%$ by weight of cement and in second part nanosilica was added up to $5 \%$ by weight of cement to high volume fly ash of $70 \%$ replacement. The superplastisizer was added to improve the workability. The corresponding mix proportions are shown in Table 2.

Table 2: Mixtures proportions by ratio per dry-mix of rubbercrete.

\begin{tabular}{|c|c|c|c|c|c|}
\hline \multirow{2}{*}{ Mixture reference } & \multicolumn{3}{|c|}{ Cementitious materials } & \multirow{2}{*}{ FA } & \multirow{2}{*}{ w/c } \\
\cline { 2 - 4 } & $\mathrm{C}$ & $\mathrm{F}$ & $\mathrm{N}$ & & \\
\hline 0FON & 1 & 0 & 0 & 2.5 & 0.38 \\
\hline $0.1 \mathrm{FON}$ & 0.9 & 0.1 & 0 & 2.5 & 0.38 \\
\hline $0.2 \mathrm{FON}$ & 0.8 & 0.2 & 0 & 2.5 & 0.38 \\
\hline $0.3 F 0 \mathrm{~N}$ & 0.7 & 0.3 & 0 & 2.5 & 0.38 \\
\hline $0.4 \mathrm{FFN}$ & 0.6 & 0.4 & 0 & 2.5 & 0.38 \\
\hline $0.5 \mathrm{FON}$ & 0.5 & 0.5 & 0 & 2.5 & 0.38 \\
\hline $0.6 \mathrm{~F} 0 \mathrm{~N}$ & 0.4 & 0.6 & 0 & 2.5 & 0.38 \\
\hline $0.7 F 0 \mathrm{~N}$ & 0.3 & 0.7 & 0 & 2.5 & 0.38 \\
\hline $0.8 F 0 \mathrm{~N}$ & 0.2 & 0.8 & 0 & 2.5 & 0.38 \\
\hline $0.9 F 0 \mathrm{~N}$ & 0.1 & 0.9 & 0 & 2.5 & 0.38 \\
\hline $0.7 F 0.01 \mathrm{~N}$ & 0.3 & 0.7 & 0.01 & 2.5 & 0.38 \\
\hline $0.7 F 0.02 \mathrm{~N}$ & 0.3 & 0.7 & 0.02 & 2.5 & 0.38 \\
\hline $0.7 F 0.03 \mathrm{~N}$ & 0.3 & 0.7 & 0.03 & 2.5 & 0.38 \\
\hline $0.7 F 0.04 \mathrm{~N}$ & 0.3 & 0.7 & 0.04 & 2.5 & 0.38 \\
\hline $0.7 F 0.05 \mathrm{~N}$ & 0.3 & 0.7 & 0.05 & 2.5 & 0.38 \\
\hline & & & & & \\
\hline
\end{tabular}

\section{Experimental programme Slump flow test}

The flow property cement mortar using polycarboxylic based super plasticizers were defined by slump flow. A mini slump flow test was carried out to ensure the flowability of mortar according to the EFNARC guidelines. The test set up is as shown in the Figure 1. The mini slump cone was positioned at the centre of base plate and it was filled with fresh mortar mix, immediately lifting the cone, the mortar spreads on the steel plate. The average diameter (in $\mathrm{mm}$ ) was measured to know the slump flow as shown in Figure 2. The spread mortar was checked visually for segregation. The self compacting 
mortars were designed for the slump flow diameter of 240$260 \mathrm{~mm}$ which was obtained by varying in amounts of SP. The SP contents for slump flow are summarized in the Table 3.

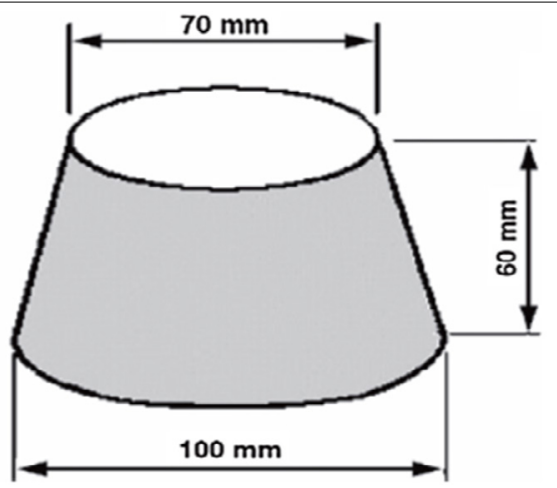

Figure 1: slump flow test setup

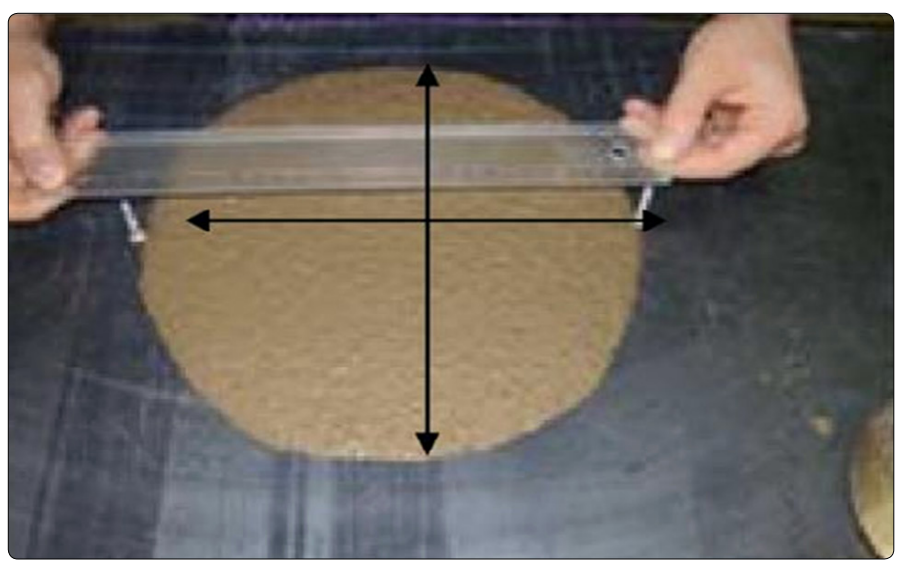

Figure 2: Slump measurements

From the Table 3 , it can be clearly noticed that fly ash replacement to the cement had enhanced flowability, $90 \%$ replacement of cement in mortar has the better workability which could be observed by its least demand of SP. However, when nano-silica was added in percentages from 0 to 5 , SP required was increased as the nano silica addition rises. The mixtures became harder as the nanosilica content increased; it can be observed from the Table 3 that SP required for $5 \%$ addition of nano silica has increased to $2.5 \%$, this clearly shows that the addition of nanosilica affected the workability due to its higher specific surface area.

Table 3: Slump flow for SP addition

\begin{tabular}{|c|c|c|}
\hline Mixture & SP $\%$ & Slump flow \\
\hline OFON & 0.5 & 250 \\
\hline $0.1 F 0 N$ & 0.45 & 255 \\
\hline $0.2 F 0 N$ & 0.4 & 250 \\
\hline $0.3 F 0 N$ & 0.35 & 255 \\
\hline $0.4 F 0 N$ & 0.3 & 248 \\
\hline $0.5 F 0 N$ & 0.25 & 253 \\
\hline $0.6 F 0 N$ & 0.2 & 257 \\
\hline $0.7 F 0 N$ & 0.15 & 250 \\
\hline $0.8 F 0 N$ & 0.15 & 245 \\
\hline $0.9 F 0 N$ & 0.15 & 240 \\
\hline $0.7 F 0.01 N$ & 0.5 & 255 \\
\hline $0.7 F 0.02 N$ & 0.8 & 260 \\
\hline $0.7 F 0.03 N$ & 1.2 & 250 \\
\hline $0.7 F 0.04 N$ & 1.7 & 252 \\
\hline $0.7 F 0.05 N$ & 2.5 & 255 \\
\hline & & \\
\hline
\end{tabular}

\subsection{Compression strength}

The compression strength test on cement mortar cubes were carried out for all the 15 mixtures. For each mix 3 cubes

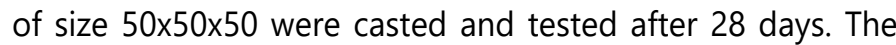
variation of compression strength with replacement of fly ash and nanosilica are shown in Figures $3 \& 4$.

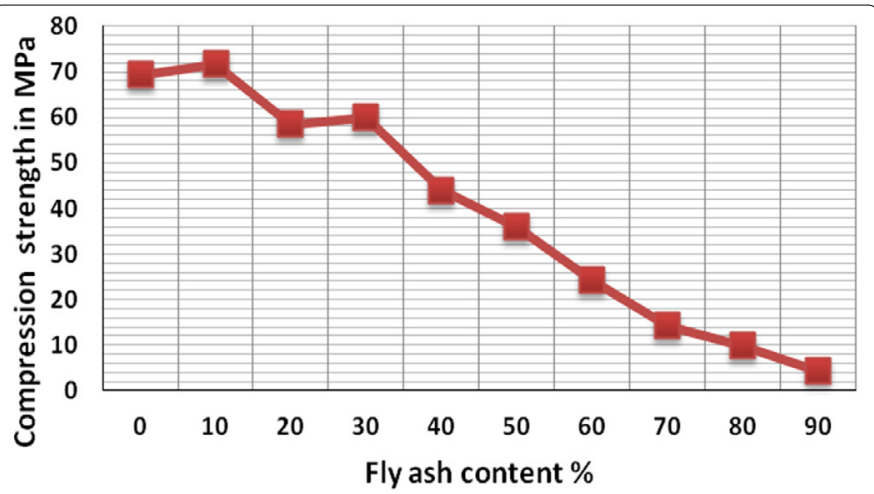

Figure 3: compressive strength versus fly ash replacement

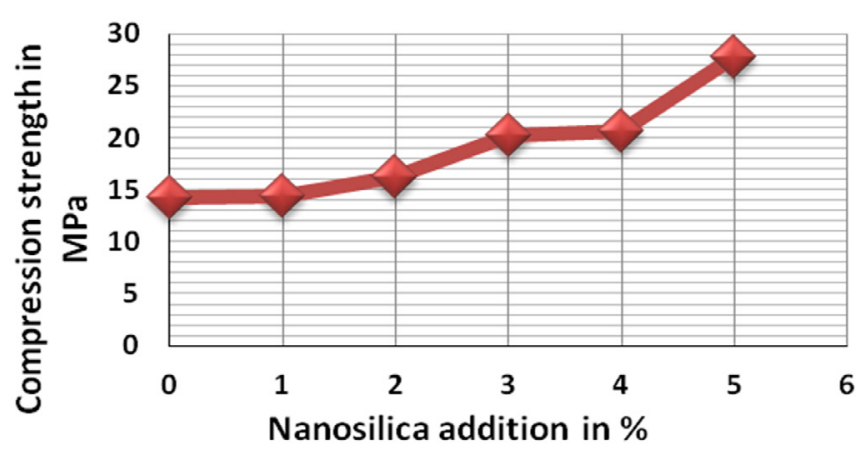

Figure 4: Compressive strength versus nano-silica addition

Figure 3, shows the relation between compressive strength of mortar and fly ash replacement to cement with zero addition of nanosilica has been plotted. Here it can be observed that the general trend of diminishing the strength as the fly ash replacement increases but at $10 \%$ replacement it exhibited a highest strength as compared with all other mixtures. $1 / 16^{\text {th }}$ of compression strength was decreased when compared the 0 and $90 \%$ of fly ash replacement. It shows that fly ash develops the low early strength at higher percentage replacement.

In Figure 4, the line diagram had been plotted compression strength against the nanosilica addition for high volume replacement of $70 \%$ fly ash. The strength has improved as the nanosilica addition increased. 94\% of compression strength boosted when compared with $0 \%$ and $5 \%$ addition of nanosilica. This indicated that nano silica high pozzolanic reaction, filler effect, improvement of the interfacial transition zone between the cement paste and activation of fly ash pozzolanic reactivity.

\section{Conclusions}

The current research draws the following conclusion for the addition silica fume in high volume fly ash cement mortar. 
Fly ash improved the workability of self compacting mortar but at higher volume replacements the compression strength at 28 days has drastically reduced.

The addition of nanosilica affected negatively on flowability of self compacting mortar. Nanosilica mitigated the strength loss due to fly ash due to its high pozzolanic activity, its filler effect improved the interfacial transition zone between the cement paste.

\section{References}

1. Toutanji H, McNeil S, Bayasi Z. Chloride permeability and impact resistance of polypropylene-fiber-reinforced silica fume concrete. Cem Concr Res. 1998; 28(7) : 961-68. doi: 10.1016/S0008-8846(98)00073-8

2. Dotto JMR, De Abreu AG, Dal Molin DCC, Müller IL. Influence of silica fume addition on concretes physical properties and on corrosion behaviour of reinforcement bars. Cem Concr Compos. 2006; 26(1): 31-39. doi: 10.1016/S0958-9465(02)00120-8

3. Mitchell DRG, Hinczak I, Day RA. Interaction of silica fume with calcium hydroxide solutions and hydrated cement pastes. Cem Concr Res. 1998; 28(11): 1571-84. doi: 10.1016/S0008-8846(98)00133-1

4. Papadakis VG. Experimental investigation and theoretical modeling of silica fume activity in concrete. Cem Concr Res. 1999; 29(1): 79-86. doi: 10.1016/S0008-8846(98)00171-9

5. Duval R, Kadri EH. Influence of silica fume on the workability and the compressive strength of high-performance concretes. Cem Concr Res. 1998; 28(4): 533-47. doi: 10.1016/S0008-8846(98)00010-6

6. Qing Y, Zenan Z, Deyu K, Rongshen C. Influence of nano-SiO2 addition on properties of hardened cement paste as compared with silica fume. Constr Build Mater. 2007; 21(3): 539-45. doi: 10.1016/j.conbuildmat.2005.09.001

7. Li G, Properties of high-volume fly ash concrete incorporating nano-SiO 2. Cement and Concrete research. 2004; 34(6): 1043-1049. doi: 10.1016/j. cemconres.2003.11.013

8. Givi AN, Abdul Rashid S, Aziz FNA, Mohd Salleh MA. Experimental investigation of the size effects of $\mathrm{SiO}_{2}$ nano-particles on the mechanical properties of binary blended concrete. Composites Part B: Engineering, 2010; 41(8):673-677. doi: 10.1016/j.compositesb.2010.08.003
9. Li H, Xiao HG, Yuan J, Ou JP. Microstructure of cement mortar with nanoparticles. Compos PartB-Eng.2004;35(2):185-89. doi: 10.1016/ S1359-8368(03)00052-

10. Li H, Xiao HG, Ou JP. A study on mechanical and pressure-sensitive properties of cement mortar with nanophase materials. Cem Concr Res. 2004; 34(3): 435-38. doi: 10.1016/j.cemconres.2003.08.025

11. Li $\mathrm{H}$, Zhang $\mathrm{MH}$, Ou JP. Abrasion resistance of concrete containing nanoparticles for pavement. Wear. 2006; 260(11-12): 1262-66. doi: 10.1016/j.wear.2005.08.006

12. Li $\mathrm{H}$, Zhang $\mathrm{MH}, \mathrm{Ou}$ JP. Flexural fatigue performance of concrete containing nano-particles for pavement. Int J Fatigue. 2007; 29(7): 1292301. doi: 10.1016/j.jifatigue.2006.10.004

13. Mondal P, Shah SP, Marks L. A reliable technique to determine the local mechanical properties at the nanoscale for cementitious materials. Cem Concr Res. 2007; 37:1440-44 doi: 10.1016/j.cemconres.2007.07.001

14. Senff L, Labrincha JA, Ferreira VM, Hotza D, Repette WL. Effect of nanosilica on rheology and fresh properties of cement pastes and mortars. Constr Build Mater. 2009; 23(7): 2489-91. doi: 10.1016/j. conbuildmat.2009.02.005

15. Jo BW, Kim CH, Tae GH, Park JB. Characteristics of cement mortar with nano- SiO2 particles. Constr Build Mater. 2007; 21(6): 1351-55. doi: 10.1016/j.conbuildmat.2005.12.020

16. Chen RS, Ye Q. Research on the comparison of properties of hardened cement paste between nano-SiO2 and silica fume added. Concrete 2002;1:7-10.

17. Tang $\mathrm{M}, \mathrm{Ba} \mathrm{H}$, Li Y. Study on compound effect of silica fume and nanoSiOx for cement composite materials. J Chin Ceram Soc. 2003; 31(5): 523-527.

18. Lin DF, Tsai MC. The effects of nanomaterials on microstructures of sludge ash cement paste. J Air Waste Manage Assoc. 2006; 56(8): 11461154.

19. Shih JY, Chang TP, Hsiao TC. Effect of nanosilica on characterization of Portland cement composite. Mater Sci Eng A - Struct. 2006; 424(1-2): 266-74. doi: 10.1016/j.msea.2006.03.010

20. Ji T. Preliminary study on the water permeability and microstructure of concrete incorporating nano-SiO2. Cem Concr Res. 2005; 35(10): 194347. doi: 10.1016/j.cemconres.2005.07.004 